\section{Semiquantitative analysis of line blot assay for myositis-specific and myositis-associated antibodies: a better performance?}

We read with interest the letter of Espinosa-Ortega $\mathrm{F}$ et $a l^{1}$ comparing line immunoblot assay (LIA) and immunoprecipitation (IP) performance in the detection of myositis-specific antibody (MSA) and myositis-associated antibody (MAA). The authors found a global moderate agreement between tests, with a very good agreement for anti-signal recognition particle (SRP), anti-Ku and anti-small ubiquitin-like modifier activating enzyme (SAE1); a good agreement for anti-hystidil-tRNA synthetase (Jo-1) and a moderate agreement for anti-PM/Scl, anti-melanoma differentiation-associated gene 5 (MDA5) and anti-transcription intermediary factor 1 (TIF1 gamma).

We previously analysed the performance of LIA (Euroline Autoimmune Inflammatory Myopathies $15 \mathrm{Ag}$ (IgG) Euroimmun, Lubeck, Germany) and IP, revealing a lower global agreement (k:0.30), and different rate of agreement for single specificities, ${ }^{2}$ compared with Espinosa-Ortega observation. In particular, we found a lower agreement rate for anti-Jo-1, PM/Scl and anti-Ku and higher agreement rate for anti-MDA-5, anti-TIF1 gamma and anti-Mi-2. Although the nature of antigens was the same (ie, native for Jo-1 and recombinant for others), we tried to find a reason for such discrepancies, separately analysing the concordance basing on the semiquantitative level of positivities of LIA. Considering only high positive $(+++)$ values, we obtained a better agreement for anti-Mi-2 antibodies (from global k: 0.50 to high-positive k: 0.79) and anti-MDA-5 (from global k:0.63 to high-positive k:0.85). No difference of agreement rate was observed between tests if considering only high or moderate/ high positivities by LIA for anti-Jo-1, anti-nuclear matrix protein (NXP-2) and anti-TIF1 gamma. No comparisons have been made for non-Jo-1 anti-synthetases antibodies, anti-SRP and anti-SAE due to low number of positive sera.

The introduction of commercial LIA improved the diagnostic accuracy of myositis patients, given that the routine use of IP is very hard in clinical practice. Anyway, some discrepancies between laboratories still remains, maybe due to the known lack of analyte-specific controls and calibrators with a possible inter-manufacturers variability. ${ }^{3}$ Maybe, considering only high or moderate positivities could help the clinician to avoid false positive, in particular when multiple MSA specificities have been detected, considered a rare event in inflammatory myositides. ${ }^{4}$

Ilaria Cavazzana $\odot{ }^{1}$ Micaela Fredi, ${ }^{1,2}$ Franco Franceschini ${ }^{1,2}$

${ }^{1}$ Rheumatology and Clinical Immunology Unit, ASST Spedali Civili of Brescia, Brescia, Italy

${ }^{2}$ Department of Clinical and Experimental Science, University of Brescia, Brescia, Italy

Correspondence to Dr llaria Cavazzana, Rheumatology and Clinical Immunology, ASST Spedali Civili of Brescia, Brescia 25100, Italy; ilariacava@virgilio.it

Contributors IC performed the data analyses and wrote the letter. MF analyzed the data. FF had the original idea to perform the semiquantitative analyses of the LIA results to modify the agreement rate between LIA and immunoprecipitation.

Funding The authors have not declared a specific grant for this research from any funding agency in the public, commercial or not-for-profit sectors.

Competing interests None declared.

Patient consent for publication Not required.

Provenance and peer review Not commissioned; internally peer reviewed.

(c) Author(s) (or their employer(s)) 2020. No commercial re-use. See rights and permissions. Published by BMJ.

\section{Check for updates}

To cite Cavazzana I, Fredi M, Franceschini F. Ann Rheum Dis 2020;79:e152.

Received 18 June 2019

Accepted 23 June 2019

Published Online First 15 July 2019

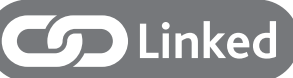

http://dx.doi.org/10.1136/annrheumdis-2019-215967

Ann Rheum Dis 2020:79:e152. doi:10.1136/annrheumdis-2019-215884

\section{ORCID iD}

Ilaria Cavazzana http://orcid.org/0000-0002-2757-7120

\section{REFERENCES}

1 Espinosa-Ortega F, Holmqvist M, Alexanderson $\mathrm{H}$, et al. Comparison of autoantibody specificities tested by a line blot assay and immunoprecipitation-based algorithm in patients with idiopathic inflammatory myopathies. Ann Rheum Dis 2019;78:858-60.

2 Cavazzana I, Fredi M, Ceribelli A, et al. Testing for myositis specific autoantibodies: Comparison between line blot and immunoprecipitation assays in 57 myositis sera. $J$ Immunol Methods 2016;433:1-5.

3 Mahler M, Fritzler MJ. Detection of myositis-specific antibodies: additional notes. Ann Rheum Dis 2019;78:e45

4 Lega J-C, Fabien N, Reynaud Q, et al. The clinical phenotype associated with myositisspecific and associated autoantibodies: a meta-analysis revisiting the so-called antisynthetase syndrome. Autoimmun Rev 2014;13:883-91. 